\title{
EL PUNTO DE VISTA Y LA METAFÍSICA*
}

Fabio Vélez Bertomeu**

E1 libro que hoy aquí nos reúne ${ }^{1}-\mathrm{y}$ es importante no perder el deíctico- declara desde su mismo título una gesta épica que resultaría de fácil incardinación en otros tiempos. Repito: otros tiempos. Solo ello, resultaría argumento suficiente para presagiar que nos hallamos ante un volumen publicado a contracorriente. Es más, y a tenor de lo anterior, no sería extraño que alguno de los aquí presentes (otro deíctico) tildase este volumen de extemporáneo. Sea como fuere, lo interesante a este respecto, lo que nos convoca incluso antes de adentrarnos en él, es el mismo título: Una metafísica para tiempos posmetafisicos. Con independencia de las reminiscencias que sugiere (Aristóteles, Kant, Habermas, etc.); o de la aparente contradicción que se desprende, con esto y con todo, los invito a sopesar, aunque a vuelo de pájaro, el sutil tramado de sus prefijos.

Si se fijan, se propone una, que no la metafísica, esto es, algo que es o está más allá o después de la física (y este meta, como nos alertó en su día P. Aubenque, se podía leer de varias maneras). ${ }^{2}$ Metafísica,

* Se ha decidido mantener el tono oral de la presentación.

** Departamento Académico de Lenguas, ITAM.

${ }^{1}$ Francisco Vicente Galán Vélez, Una metafísica para tiempos posmetafísicos, 2015, México, Universidad Iberoamericana.

${ }^{2}$ Cfr. P. Aubenque, ¿Hay que deconstruir la metafisica?, 2012, Madrid, Ediciones Encuentro. 
por tanto, para tiempos posmetafísicos, es decir, para una época - la nuestra - en la que la metafísica (o un modelo de metafísica) no tendría que darse de consuno. De fondo, efectivamente, laten los grandes problemas del pensamiento, a saber: la vigencia (o no) de una philosophia perennis, superada (o no) deconstruida (o no), que se las tiene que haber con su porvenir, con estar — como diría Ortega — a la altura de los tiempos.

Al final de la introducción, y tras haber realizado un somero repaso a los hitos más decisivos en lo referente a una crítica de la metafísica, Galán decide, nada casualmente y siguiendo la batuta de Lonergan, que el segundo Wittgenstein figure como peldaño final del camino. Y aunque efectivamente se lanza un guiño cómplice a la filosofía analítica, lo que de verdad le interesa rescatar, y de hecho rescata, no es lo que vulgarmente se identifica como la primera etapa de la escuela, caracterizada por su preocupación por las cuestiones semánticas y en estrecha cercanía con el positivismo lógico, o en otras palabras, por la búsqueda de un lenguaje ideal perfecto, sino por el cariz y el tono que reviste la escuela posteriormente, en su giro al lenguaje ordinario y por su dimensión irreductiblemente pragmática.

Si me resulta cautivador este punto de inflexión es fundamentalmente por dos motivos. Cito: "Sin poder presentar un diálogo con los detalles que el tema lo exigiría, en el presente trabajo se hace un intento por dialogar mayormente con esta última tradición" (p. 49). Así pues, Galán no solo hace hincapié en la predilección por esta tradición, desechando las restantes (al menos en cuanto al orden de relevancia), sino que se excusa por no poder adentrarse, como la cosa por otra parte exigiría, dados los límites del objeto de estudio. Pues bien, con esto presente, llama poderosamente la atención que Galán, no obstante, casi a modo de lo que en retórica se denomina una preterición, retorne sobre este asunto a mitad del libro para injertar un excurso. Y es que, 
como ya barruntaba en los primeros pasos de su obra, "el tema exigiría detalle". Así las cosas, es este punto, sin duda de inflexión, pero también de posible partida, el que se me antoja atractivo desplegar. Más en concreto, y en lo que a mí concierne, el interés se precipita en al menos dos vertientes.

La primera, inherente a la deformación filológica (todo aquello del close reading, de la estilística del detalle, etc.), me obligaría a detenerme - es decir, a no subestimar con ligereza - en este síntoma. De esta manera, tal vez forzada, presumiré que este excurso, este paréntesis, oculta, no diré algo reprimido, pero sí me atreveré a postular que tras él se guarece algo que el autor considera de valía dejar bien clarificado. Se trataría, por así decir, de no descuidar agujeros en el texto y, por consiguiente, de un zurcido de seguridad. El segundo interés que me despierta este excurso está relacionado, en cierto modo, con el papel vicario que ejerzo en esta mesa. Es decir, con el papel de representante del Departamento de Lenguas que me ha sido amablemente encomendado. En este sentido, me atrevo a sugerir que quizás no estuviera de más hacer aflorar una posible lectura que pudiera tender puentes con los intereses que atañen al departamento en cuestión. Me centraré, pues, en el lenguaje.

Comencemos. La primera pregunta que acaso se formule todo lector de un libro de metafísica, tras haber leído aquello de "el presente trabajo hace un intento de dialogar con la tradición analítica", pudiera ser esta: ¿dónde demonios se halla ese "oro" que Lonergan parece apreciar tanto en esta corriente, cuando precisamente la filosofía analítica ha ostentado orgullosa y descaradamente su cruzada contra la metafísica, bastardeándola a la mera condición de embrujo lingüístico?

Este diálogo con la filosofía analítica y, más en concreto, con la pragmática del segundo Wittgenstein, merece ser considerado con un mínimo de atención. En comunión con Heidegger (recordemos aquello del ser, sí, pero en-el-mundo), Galán nos recuerda que el gesto del segundo Wittgenstein exhibe en este sentido un parentesco manifiesto. Y, en efecto, bien mirado, ahora toda forma lo será, sí, pero de una vida concreta. Cito la breve y lúcida interpretación de Galán: "Hay muchos mundos y la verdad es abierta desde el mundo de la vida, de una forma 
de vida. Y no hay manera de ir más allá ni de encontrar algo común a todas esas formas de vida" (p. 48). Del segundo Wittgenstein, Galán recupera aquello que Lonergan considera irrenunciable para una filosofía digna de ese nombre, a saber, la historia. No será casual, por ende, que en el aparato conceptual de este encontremos expresiones como "campos de la significación" o "patrones de experiencia" que, ciertamente, remiten a los "juegos de lenguaje" wittgensteinianos. Y sin embargo, en cercanía con el proyecto kantiano, Lonergan asume del mismo modo que, si bien la metafísica dogmática debe quedar atrás, el planteamiento trascendental, que garantizaría la necesidad y la universalidad (al menos epistemológicamente), debe permanecer. Veamos el argumento de cerca y en las palabras de Galán:

Tenemos así una transformación de la postura kantiana por un nuevo énfasis "sociológico" que en gran parte arruina el propósito kantiano. Hay una destrascendentalización del sujeto trascendental kantiano para dar lugar a variantes socioculturales, siempre históricas, de los a priori kantianos. La pérdida de la dimensión universal trae la pérdida de lo normativo trascendental y la suplantación de la epistemología por una sociología del conocimiento. [p. 48]

Tras este diagnóstico, fatal en algún sentido, Galán nos saca del atolladero, del callejón sin salida, de la mano ciceroniana de Lonergan. Son sus palabras: "Solo hay que pensar de una nueva manera [y subrayo lo de 'nueva manera'] lo trascendental, lo universal y lo necesario" (p. 49).

¿Y si de esa "nueva manera" de pensar, el mentado excurso nos diera alguna pista? Probemos.

Si nos acercáramos al excurso comprobaríamos que Galán, en un gesto nuevamente de contención, resume las afinidades electivas con Wittgenstein, pero también, y esto acaso sea lo más importante, las discrepancias. Y es aquí donde el atento oído filológico descubre una pista candidata a ser perseguida. Tras enumerar los cuatro puntos que Lonergan considera más relevantes, el párrafo final se clausura con un punto y aparte, y Galán prosigue con estas palabras: "Hasta aquí llega 
la parte en la que explícitamente hay esta confrontación con las ideas del segundo Wittgenstein o con la interpretación de este. Una ulterior diferencia que encontramos" (p. 345). Despuntan en esta observación dos matices susceptibles de ser examinados más de cerca. En primer lugar, Galán parece dejar a un lado a Lonergan y a ciertos intérpretes de Wittgenstein (McKinon, Beards, McShane, Meynell), esto es, lo explícito; y en segundo, todo apunta a que va a ser él quien tome la iniciativa (aunque desde la segunda persona del plural), pues es posible que resten todavía diferencias importantes.

[E]ncontramos que Wittgenstein niega que haya algo común en todos los juegos; solo hay "parecidos de familia". Lonergan aceptaría que no hay un juego que controle todos los juegos. Cada uno tiene sus reglas. Cada campo tiene su autonomía propia. Cada patrón es igualmente importante y necesario en la vida humana. Pero lo que es falso es entender esta tesis como incomunicabilidad de los juegos. Sí hay algo que penetra y subyace a todos los contenidos y tal es la noción proteica de ser, tal es el deseo puro de conocer [...] Frente a tal limitación, al igual que en Kant, siempre preguntaríamos, ¿y qué hay más allá?, ¿cómo se juega allá? [...] En efecto, siempre puedo preguntar por lo más allá. [p. 345]

Lo que me interesa de este pasaje son las cabriolas conceptuales, la tensión por cuadrar el círculo. Según Galán, no ha lugar a un “juego de juegos" que dictaría las reglas particulares de cada juego, pues no hay nada común a todos ellos; ahora bien, esto no tendría necesariamente que redundar en una incomunicabilidad entre los mismos, y de ahí la propuesta, a la Apel, de un "juego trascendental". ${ }^{3} \mathrm{O}$ dicho de otra manera, y sirviéndome de una suerte de antinomia: no hay metalenguaje, pero tampoco hay incomensurabilidad. ¿Una tercera vía, pues? Según Galán, siempre cabría asomarnos al límite de cada juego y otear desde un horizonte común.

Queda patente en todo el volumen la denodada pulsión por divulgar sin vulgarizar, por explicar sin reducir. De ahí puede inferirse legítimamente el gusto del autor por la orfebrería conceptual. Nos hallamos, por tanto, ante un artesano que no da puntada sin hilo y que teje

${ }^{3}$ Cfr. Karl Otto Apel, La transformación de la filosofia, 1985, Madrid, Taurus. 
finamente su pieza. Se atisba asimismo el esfuerzo requerido al lector para poder seguirle hasta en los vericuetos más inusitados. Es más, podría conjeturarse incluso la reacción del lector deconstruccionista (ya lo puedo imaginar): bizqueando al toparse con una promesa de reconciliación entre lo trascendental y lo histórico para, acto seguido, peinar pacientemente el texto, con una sonrisa complaciente dibujada en el rostro, como la de quien se sabe vencedor antes de la batalla, en busca del esperado tropiezo, del eureka. Y huelga advertirle cuanto antes, arruinarle la fiesta: no lo hallará. Galán es un entrenado acróbata que domina la cuerda floja; se entiende, pues, que junto a su amor por el riesgo, lo acompañe siempre la amenaza de la caída, de la contradictio in terminis.

Antes de terminar, me gustaría compartir una inquietud, más que una discrepancia. Me ayudaré para ello del "más allá" antes apelado. Más allá... meta... seguimos en coordenadas metafísicas. Para ello, y quizás desde la posición de un tercero excluso, me gustaría reorientar el problema, no tanto desde una posición dilemática, cuanto más bien aporética. Es decir: no tanto desde el $o \mathrm{~A} o \mathrm{~B}$, sino $n i \mathrm{~A} n i \mathrm{~B}$. Para ello me serviré del pensamiento de Davidson.

Una manera de recopilar lo sugerido podría ser más o menos la que sigue: si el segundo Wittgenstein, en virtud de las distintas formas de vida y sus respectivos “juegos del lenguaje”, situaba el límite en el "más acá" de cada juego, holísticamente podríamos decir (y de esta manera, cada juego tendría una racionalidad propia, una coherencia interna). Lonergan, pace Apel, aventuraba la posibilidad, a pesar del límite presuntamente infranqueable, de un ir "más allá" (un "más allá" obviamente trascendental, pero sin por ello perder el contrapeso pragmático). El primero nos conducía inexorablemente a la inconmensurabilidad y al relativismo, mientras que el segundo, por el contrario, si bien siempre en un sentido regulativo, abría las puertas a un posible entendimiento dialéctico, en virtud de una mínima racionalidad compartida, un consenso. 
Pues bien, el escrutinio acerado de Davidson (me refiero en concreto al Davidson de la década de 1970) ${ }^{4}$ desemboca en un desplazamiento del problema, una vez comprendida la naturaleza aporética de sendas alternativas. Hagamos el intento de resumir su propuesta. Si así lo hiciéramos, concluiríamos que, por un lado, si la propuesta de Wittgenstein fuera asumida radicalmente $-\mathrm{o}$ si se quiere, en toda su literalidad-, entonces ni tan siquiera podría abrirse la posibilidad para juzgar si de veras estamos lidiando con un "juego de lenguaje" distinto. Para Davidson, todo intérprete necesita presumir ciertas creencias (aunque no todas) y cierta racionalidad en el interlocutor para poder empezar a divisar que los sonidos, ruidos, etc., que este mismo emite puedan ser indicios de un lenguaje. Sin este mínimo, que Davidson denomina "principio de caridad", la radicalidad sería tal que nos impediría incluso el poder empezar a reconocer algo. Por consiguiente, deduce Davidson, el relativismo y la inconmensurabilidad serían insostenibles.

Ahora bien, por otro lado, si escrutamos con mayor detenimiento el "principio de caridad" — se entiende, más allá de su aparente evidencia—, concluiríamos que estamos sobreentendiendo la racionalidad de manera parcial, sinecdóquica y, en consecuencia, facultando un sospechoso quid pro quo. Es decir, habría que presumir, si no toda, parte de mi racionalidad y mis creencias en mi interlocutor, lo cual, por de pronto, sería presumir demasiado. Nos las habemos, quizá puedan ya adelantarlo, con la crítica etnocentrista que ha recibido el pragmatismo trascendental de Apel y, en menor medida, el de Habermas; aquello de que "su" razón — occidental, ilustrada, etc.- no tiene por qué ser la única razón. La cuestión que está operando de fondo, por aterrizarlo en ejemplos concretos, es la de si cuando tratamos de entender la religión antigua en Grecia o la filosofía india o la medicina china las estamos entendiendo realmente en su alteridad, o si, por el contrario, no estaremos imperialista y negligentemente proyectando y maximizando nuestras categorías. (Es más, ¿podemos hablar de "religión” griega, de "filosofía" india, de "medicina" china? Para no desplazarnos tan lejos, a horizontes tan exóticos, ¿cuando hablamos hoy de "justicia”

${ }^{4}$ Donald Davidson, De la verdad y su interpretación, 1990, Barcelona, Gedisa. 
aymara, estamos entendiendo eso que nombramos; le hacemos justicia a su justicia?)

Pero retomemos el cabo. Todo lo anterior nos sitúa en el incómodo espacio de la paradoja, a saber: o no puedo conocer lo otro (y, por lo tanto, habría que preguntarse igualmente cómo es que Wittgenstein, sin embargo, es capaz de dar cuenta de los diferentes juegos de lenguaje) ${ }^{5}$ o si lo reconozco, tengo que asumir que no hago más que presuponer en el otro lo que ya está operando en mí, es decir, no hago más que re-conocer, corroborar, en definitiva, apropiarme del yo de lo otro.

De la primera paradoja no comentaré nada, sería una discusión larga y prolija, pero por cercarla de algún modo, lo que cabría replicar podría compendiarse de la siguiente manera: esta tradición tendría que dar cuenta de la "contradicción performativa" en su discurso. Solamente adelantaré, tomando la estela derridiana, una respuesta en forma de pregunta: ¿cómo deconstruir la metafísica si no con el lenguaje metafísico? ¿Acudir a otro lenguaje, no supondría un afuera y un metalenguaje? Pero quedémonos aquí, por lo que a esta tradición respecta. Más relevante es, en este momento, centrarse en la segunda.

Para ello echaré mano, aprovechando la reciente visita de Coetzee

144 a México, ${ }^{6}$ de la literatura. Si ustedes recuerdan, en la novela titulada Vida y época de Michael K, el protagonista — un trasunto del insecto de Kafka, del Bartleby de Melville, más algunos toques, diría yo, de Thoreau y algo más que lo haría único - decide resistir al destino que le corresponde por nacimiento (una vida de pobreza, persecución y guerra). Entre sus varias estrategias de resistencia, destaca para este caso una de ellas, a saber, la de reducir su comunicación con los otros al mínimo. Si hacen memoria, convendrán en que los que le rodean, exasperados, lo animan a hablar; tanto los que desean inculparlo como los que desean exculparlo (quién sabe de qué, en ambos casos). En suma, todos lo exhortan a contar su versión de los hechos y de su vida (una historia, todo sea dicho, de la que él solo es capaz de emitir jirones) y

${ }^{5}$ Cfr. Ludwig Wittgenstein, Investigaciones filosóficas, 1988, Barcelona, México, Crítica, UNAM, $\S 65$.

${ }^{6}$ A propósito de la concesión del honoris causa por la Universidad Iberoamericana. 
que, todos a su vez, malinterpretan. A pocas páginas del final, el protagonista reflexiona sobre su particular vagabundeo: primero la ciudad, después el campo, más tarde los centros de reeducación, las derivaciones a los hospitales, para al final terminar de nuevo en la ciudad, aunque varado en una playa. Son sus palabras: "Me he convertido en un objeto de caridad. A todas partes donde voy hay personas que quieren practicar conmigo sus diferentes formas de caridad". ${ }^{7}$ Entendamos por caridad, aquí, formas de comprensión. Lo más intrigante de todo ello es que solo ha sido capaz de evadir su destino gracias a la incomprensión generada en los otros; solo así ha logrado, como ansiaba, salir de su época, de la rueda de la historia, y dejarse llevar por el tiempo. Vislumbra entonces que todavía le falta un paso para cortar por completo el cordón umbilical con la sociedad, ese reducto de caridad, y este eslabón pasa justamente por la incomunicación, por el silencio absoluto.

Otra posible manera de ejemplificar esta contraposición de perspectivas, esta guerra de trincheras, podría ser traer a colación el encuentro infructuoso (o no, según desde qué parte se mire) entre Gadamer y Derrida, entre la hermenéutica y la deconstrucción, en 1981 en París. ${ }^{8}$ De aquel célebre des-encuentro, en el que uno pugnaba por sentar las bases para un diálogo y el otro por mostrar un desacuerdo estructural — de fondo, efectivamente, el verstehen y la différance-, no podemos ocuparnos ahora. Sea como fuere, lo interesante es que un año antes de su muerte, en 2003, Derrida publicó un pequeño texto en el que ajusta cuentas con aquel cortocircuito acontecido, y lo tituló nada fortuitamente Carneros. El diálogo interrumpido. Entre dos infinitos, el poema. No era accidental el subtítulo, tampoco la elección del género para desplegarlo (la poesía), pues nuevamente estaba en juego la literatura. Y recuerden que ya Gadamer había señalado a propósito de la misma, y en virtud de la producción de "textos eminentes", la dificultad para reducirlos a un sentido y, por ende, para consensuar interpretaciones. En cualquier caso, el propósito de haber traído a la memoria este

${ }^{7}$ J. M. Coetzee, Vida y época de Michael K, 2015, Barcelona, Penguin Random House, p. 185.

${ }^{8}$ Diálogo y deconstrucción: Los límites del encuentro entre Gadamer y Derrida, 1998, Madrid, Cuaderno Gris. 
sintomático suceso es que Derrida, al igual que Michel K, señalaba la necesidad del silencio para el éxito de su causa. Recordemos la valoración retrospectiva del argelino: "el logro [del encuentro] residió en su carácter fallido [...] para mí, la mayoría de las veces, de un modo interior y aparentemente mudo". 9

Si me he demorado en todas estas manifestaciones, es porque el asunto que el libro se trae entre manos es lisa y llanamente complejo. Antes de terminar, una última filigrana, no mía, sino de Francisco Vicente Galán. De todo lo que hemos venido diciendo es posible desprender dos posturas filosóficas: lo que Galán denomina el "punto de vista universal” y lo que, ayudándonos de Rorty, nombraríamos el "punto de vista particular". ${ }^{10} \mathrm{Si}$ escuchamos atentamente, notaremos que nos enfrentamos a un oxímoron y a un pleonasmo. Si es un punto de vista no puede ser universal, y si es punto de vista indefectiblemente tiene que ser particular. Finalizo lanzando, como una botella al mar, estas dos preguntas: ¿Y si el problema nace del punto de vista? ¿Acaso no implica ya este la posibilidad de lo neutral y, por tanto, una suerte de ojo omnisciente?

${ }^{9}$ Jacques Derrida, Béliers. Le dialogue ininterrompu: Entre deux infinis, le poème, 2003, París, Galilée, p. 19.

${ }^{10}$ Richard Rorty, Ironía, contingencia y solidaridad, 1992, Barcelona, Paidós. 